\title{
Lembranças das abordagens na aquisição de LE/L2 de falantes e aprendizes e o fazer atual como professores ${ }^{1}$
}

Elaine Ferreira do Vale Borges

Faculdade de Educação da Universidade de São Paulo (Doutoranda)

\begin{abstract}
RESUMO: Este artigo objetivou diagnosticar as referências às abordagens de ensino de LEs que permearam os processos de aquisição de falantes e aprendizes de LE/L2 através de coletas de narrativas de histórias de vida; e refletir sobre como, ora atuando como professores de LEs, essas lembranças influenciaram o uso de uma determinada abordagem em sala de aula. Em especial, procurou-se observar as mençôes ao ensino de línguas para fins específicos como uma abordagem ou metodologia da abordagem comunicativa. Os resultados mostraram que, em geral, foi a abordagem gramatical que permeou os processos de aquisição de LE/L2 e de ensino de LEs, porém com uma mudança significativa de abordagem nos professores de LEs com mestrado em Lingüística Aplicada. Pouco mencionado nas narrativas, o ensino de línguas para fins específicos foi considerado como uma metodologia da abordagem comunicativa.
\end{abstract}

PALAVRAS-CHAVE: narrativa, abordagem de ensino; aquisição de LE/L2

\section{Introdução}

No complexo processo de ensino/aprendizagem de língua estrangeira (LE) e/ou segunda língua (L2) pode-se constatar um emaranhado de fatores como, por exemplo, questōes relacionadas à afetividade (CARDOSO; LIMA, 2006), aos erros e/ou estratégias de aprendizagem (BOHN, 2006), ao papel das atividades, à instrução formal/informal, à identidade (ANDRADE, 2006), às competências de professores/alunos (FRANCO; ALVARENGA, 2006), à cultura de ensinar/aprender, às abordagens de ensino/aprendizagem (ABRAHÃO, 1996; ALMEIDA FILHO, 1999; CARDOSO, 2002), às crenças sobre o ensinar/aprender de professores/alunos (BARCELOS, 2006), à autonomia

\footnotetext{
${ }^{1}$ Gostaria de agradecer aos falantes e aprendizes de LE/L2 que gentilmente cederam suas belas histórias de vida, sem as quais este trabalho não teria sido possível; e também à Profa. Dra. Márcia Aparecida Amador Mascia pela grande ajuda na coleta de parte das narrativas; e em especial à Profa. Dra. Vera Lúcia Menezes de Oliveira e Paiva pelas oportunidades que culminaram no desenvolvimento deste artigo.
} 
(PAIVA, 2006); entre outros, que compõem ora o aprender do aluno ora o fazer do professor.

No entanto, é possivelmente na compreensão de como se aprende uma língua que se pode refletir no como se ensina essa língua. Uma maneira de se perceber esse processo de aquisição é através da Pesquisa Narrativa, em que os narradores (aprendizes/falantes de LE/L2) "são convidados a reverem e organizarem suas experiências pedagógicas e de vida - um movimento que parte de dentro para fora - de 'si próprio' para trás e para frente, em um traçar de suas próprias linhas de vida" (CLANDININ; CONNELLY, 1998 apud TELLES, 2002, p. 18). Esse, em poucas palavras, é o grande desafio proposto pelo projeto AMFALE $^{2}$ (Aprendendo com memórias de falantes e aprendizes de línguas estrangeiras), do qual este artigo deriva a partir de investigações e encaminhamentos.

Sabendo-se, então, que as narrativas e/ou histórias de vida de aprendizes e falantes de LE/L2 podem revelar situações preciosas para a análise científica, as abordagens - um dos fatores no processo de ensino/aprendizagem de línguas estrangeiras (LEs) - receberam especial atenção neste artigo, numa tentativa de se diagnosticar também o "fazer atual" dos narradores (professores de LEs préserviço e em serviço), e as relações possíveis que se estabeleceram entre o "passado" dos mesmos (como aprendizes de LEs) e o "presente" (como professores de LEs).

Para tanto, partiu-se da compreensão do termo abordagem, descrito por Anthony (1965, p. 8, tradução nossa), como "um conjunto de suposições correlativas tratando da natureza da linguagem e do ensino-aprendizagem" de LEs. Para o autor, a abordagem "descreve a natureza do assunto em questão a ser ensinado", sustentando "um ponto de vista, uma filosofia, um ato de fé, algo que se acredita, mas que não se pode necessariamente provar". Ainda, segundo Anthony (op. cit.) a abordagem é "freqüentemente indiscutível, exceto em termos da efetividade dos métodos que originam dela". O autor estabelece o uso hierárquico dos termos abordagem (axiomática), método (processual) e técnica (particular), entendendo que a técnica ("uma habilidade particular, um planejamento, ou uma maneira de fazer para alcançar um objetivo imediato") projeta o método ("um plano global para a apresentação ordenada do material da língua, linguagem"), que deve ser consistente com a abordagem (termo mais abrangente e dominante). Assim, uma técnica levaria a cabo um método que deveria ser consistente com uma abordagem. Para Anthony (op. cit.) a re-

2 http://www.veramenezes.com/amfale.htm. 
alocação hierárquica em termos das definições dos termos "abordagem", "método" e "técnica", e limites para os seus usos, seria um esforço necessário para as discussóes profissionais sobre conceitos no campo de ensino de línguas, evitando, assim, maiores confusões terminológicas.

Porém, apesar de se considerar as definições propostas por Anthony (op. cit.) como ponto de partida para as reflexóes neste artigo e também de sua preocupação com a terminologia, utilizar-se-á aqui o termo enfoque em um sentido neutro para designar abordagem e/ou método (enfoque específico, para o método e/ou abordagem instrumental; e enfoque geral, para o método e/ou abordagem comunicativa). Objetivando-se uma padronização utilizar-se-á também o termo enfoque gramatical, referindo-se ao ensino focado puramente na forma, embasado por uma visão sistêmico-gramatical e behaviorista.

O termo enfoque aparece primeiramente em Castaños (1993, p. 75) para designar a abordagem comunicativa, momento em que se discute se o "ensino de língua com propósitos específicos" representa "uma forma do enfoque comunicativo" ou "um enfoque diferente e oposto". Para muitos estudiosos da área (pesquisadores e professores de LEs) os dois enfoques destacados (específico e geral) são, e sempre foram, considerados como métodos de uma mesma abordagem, a comunicativa. Essa, na percepção deste artigo, é uma discussão complexa e ainda atual ${ }^{3}$ (WILKINS, 1976; HUTCHINSON; WATERS, 1984, 1987; HOWATT, 1988; WATERS, 1993; WILLIANS; BURDEN, 1997; CELANI, 1997; WIDDOWSON, 1998; HOWATT; WIDDOWSON, 2004; BORGES, 2003; RAMOS, 2005), que vem sendo apresentada dentro do que se convencionou chamar de movimento comunicativo de lingua. Movimento que se inicia a partir da década de 1970 e se expande no Brasil a partir de 1978, e mais enfaticamente na década de 1980, com a implementação do Projeto Ensino Inglês Instrumental em Universidades Brasileiras com várias publicações sobre o tema na área. Em decorrência desse projeto verificar-se, também (cf. BORGES, 2003), os encaminhamentos do enfoque especifico na elaboração dos Parâmetros Curriculares Nacionais de Língua Estrangeira (PCN-LE; SEF/MEC,1998) - documento oficial do Ministério da Educação voltado para o ensino fundamental e médio da rede pública.

\footnotetext{
${ }^{3}$ Discussão que este artigo objetiva também desenvolver, só que no limite das narrativas analisadas e do contexto brasileiro. Enfatizando que os resultados obtidos com esse estudo irão compor parte das reflexôes atualmente desenvolvidas no projeto de doutoramento do qual esta pesquisa está vinculada.
} 


\section{A coleta, as narradoras e o diagnóstico}

O diagnóstico implementado neste trabalho teve um viés qualitativointerpretativista, como exposto em Moita Lopes (1994, p. 331), que prevê o acesso indireto ao fato de pesquisa "através da interpretação dos vários significados que o constituem"; e possui uma sistematização diferente daquelas já encontradas em pesquisa sobre abordagens dentro da Lingüística Aplicada (ABRAHÃO, 1996; ALMEIDA FILHO, 1999; CARDOSO, 2002), pelo uso de narrativas, e tendo em vista que se objetivou, essencialmente, enfatizar apenas dois enfoques de ensino de língua: o comunicativo (enfoque geral) e o instrumental (enfoque específico). No entanto, outros métodos e/ou abordagens - como a gramatical (enfoque gramatical) - citados nas narrativas também foram consideradas.

As narrativas foram coletadas pessoalmente e por meio da Internet (via correio eletrônico) no decorrer do final do ano de 2004 e início do ano de 2007, período de duração da pesquisa. Foi solicitado aos participantes que redigissem uma narrativa sobre a sua história de vida no que se referia ao processo de ensino/aprendizagem de uma L2/LE e às lembranças sobre os métodos e abordagens envolvidas nesse processo, sendo que a referida história deveria percorrer a extensão dos anos da convivência com essa L2/LE. Foi esclarecido que não havia necessidade de citar explicitamente os nomes dos métodos e/ou abordagens, caso os mesmos lhe fossem desconhecidos e/ou esquecidos, sendo necessário, no entanto, fazer algumas menções aos tipos de atividades e/ou exercícios envolvidos no processo, para que depois a pesquisadora pudesse interpretá-las de acordo com um método e/ou abordagem específica. Após a solicitação de uma narrativa, um intervalo de tempo foi concedido para o seu recolhimento, o que acabou ocasionando na não entrega de várias delas - um dos problemas do projeto que resultou na coleta de apenas dezesseis narrativas, tendo sido, no entanto, bem maior o número de solicitaçóes. Participaram desta pesquisa, então, dezesseis narradoras $^{4}$ das quais, no ato da coleta, eram (cf. Quadro 1):

a) nove professoras de LE pré-serviço (alunas do último ano do curso de graduação em Letras): duas já lecionavam língua inglesa - todas brasileiras, aprendizes e falantes de língua inglesa (LE);

\footnotetext{
${ }^{4}$ Como todas as narrativas foram, coincidentemente, redigidas por mulheres, usaremos o termo narradora(s).
} 
b) sete professoras de LE em serviço (três com mestrado em Lingüística Aplicada; uma graduada em Letras, uma graduada em outra área que não Letras, uma em formação também em outra área que não Letras e outra com graduação em área não revelada, ${ }^{5}$ sendo que:

1) quatro lecionavam em escolas particulares de idiomas: duas ensinando língua inglesa (LE), uma ensinando língua francesa (LE) e outra língua espanhola (LE). Três brasileiras: uma aprendiz e falante de língua inglesa (LE), uma aprendiz e falante de língua francesa (LE) e, outra aprendiz e falante de língua espanhola (LE). Uma inglesa: ${ }^{6}$ aprendiz e falante de língua portuguesa (L2);

2) três já haviam lecionado inglês (LE) em escolas particulares de idiomas ou em escolas da rede estadual de ensino: todas brasileiras, aprendizes e falantes igualmente de língua inglesa (LE) .

Salientando que uma das narrativas é a da própria pesquisadora, tendo sido, inicialmente, redigida de forma livre (sem os encaminhamentos propostos às outras narrativas participantes deste projeto), com o propósito apenas de compor o conjunto de narrativas das memórias do processo de aquisição de L2/LE dos pesquisadores participantes do projeto AMFALE (como contribuição ao mesmo). O motivo para incorporá-la, depois, a este trabalho se deu pela constatação do número reduzido de narrativas coletadas (um dos problemas de pesquisa já mencionado acima) e pela mesma conter fatos narrados sobre atividades e metodologias no processo de ensino/ aprendizagem de L2/LE, tema de interesse deste artigo.

\footnotetext{
${ }^{5}$ As informações sobre a formação acadêmica de cada narradora foi considerada importante para esta pesquisa, tendo em vista que é provavelmente durante o curso de graduação em Letras e/ou no mestrado em Lingüística Aplicada que se obtém conhecimento sobre as abordagens de ensino/aprendizagem de LEs, embora esse conhecimento possa ser obtido em outros contextos também e por outros meios. Algumas informações sobre a formação e atuação profissional das narradoras foram obtidas em conversa informal antes das coletas das narrativas.

${ }^{6}$ A narrativa da participante de nacionalidade inglesa foi redigida em inglês, visto ser essa a sua língua materna (L1), e as transcriçóes de partes de seu depoimento foram traduzidas pela pesquisadora para o português, esperando, no entanto, ter sido o mais fiel possível.
} 


\section{QUADRO 1}

Distribuição das narrativas coletadas

\begin{tabular}{|c|c|c|c|c|c|c|c|c|c|}
\hline \multirow{3}{*}{$\begin{array}{l}\text { País de } \\
\text { origem } \\
\text { das nar- } \\
\text { radoras }\end{array}$} & \multirow{3}{*}{$\begin{array}{c}\text { Língua Estrangeira } \\
\text { (LE) } \\
\text { Segunda Língua } \\
\text { (L2) }\end{array}$} & \multicolumn{4}{|c|}{$\begin{array}{c}\text { Professores de LEs em serviço } \\
\text { (alunas do último ano de Letras) }\end{array}$} & \multicolumn{4}{|c|}{ Professores de LEs em serviço } \\
\hline & & \multicolumn{3}{|c|}{ Lecionando } & \multirow[t]{2}{*}{$\begin{array}{l}\text { Não } \\
\text { lecionando }\end{array}$} & \multicolumn{3}{|c|}{$\begin{array}{c}\text { Lecionando } \\
\text { Escola de idiomas }\end{array}$} & \multirow[t]{2}{*}{$\begin{array}{l}\text { Não } \\
\text { lecionando }\end{array}$} \\
\hline & & $\mathrm{LI}^{7}$ & LF & LE & & LI & LF & LE & \\
\hline Brasil & $\begin{array}{l}\text { Falante e aprendiz de } \\
\text { língua inglesa (LE) }\end{array}$ & 2 & & & 7 & 1 & & & 3 \\
\hline Brasil & $\begin{array}{l}\text { Falante e aprendiz de } \\
\text { língua francesa (LE) }\end{array}$ & & & & & & 1 & & \\
\hline Brasil & $\begin{array}{l}\text { Falante e aprendiz de } \\
\text { língua espanhola (LE) }\end{array}$ & & & & & & & 1 & \\
\hline Inglaterra & $\begin{array}{l}\text { Falante e aprendiz de } \\
\text { língua portuguesa (L2) }\end{array}$ & & & & & 1 & & & \\
\hline \multicolumn{2}{|c|}{ Total de narrativas: 16} & \multicolumn{4}{|c|}{9} & \multicolumn{4}{|c|}{7} \\
\hline
\end{tabular}

Por serem, todas, professoras de LEs (pré-serviço e/ou em serviço, lecionando ou não aulas de LEs), era esperado que as narradoras possuíssem algum conhecimento (subcompetência teórica, ALMEIDA FILHO, 1998, p. 21) sobre as abordagens, métodos e técnicas de ensino de língua, mesmo daquelas que não eram formadas em Letras ou que ainda estavam cursando a graduação; tanto que lhes foi solicitado ${ }^{8}$ previamente (como já esclarecido acima) que sinalizassem em suas narrativas quaisquer pistas (tipos de exercícios, tarefas, etc) que pudessem estar associadas às abordagens e/ou metodologias (ou elas mesmas) e pelas quais tinham tido contato durante os seus respectivos processos de aprendizagem de L2/LE; bem como pistas (para aquelas que lecionavam ou que já haviam lecionado uma LE) de suas ações em salas de aulas, como professoras de LEs.

O foco no diagnóstico da menção aos dois enfoques de ensino de LEs (geral e especifico - como enfatizado na introdução deste trabalho) teve por intenção proporcionar um pequeno panorama da atual apropriação e/ou compreensão dessas duas visões contemporâneas de ensino de língua (como métodos inseridos em uma abordagem, a comunicativa, ou como abordagens distintas) entre os professores de LEs pré- serviço e em serviço no contexto brasileiro.

\footnotetext{
${ }^{7}$ LI (Língua Inglesa), LF (Língua Francesa) e LE (Língua Espanhola).

${ }^{8}$ Salvo a narrativa da própria pesquisadora, que (como já mencionado anteriormente) foi redigida com outro propósito.
} 
Inicialmente cada narrativa foi analisada separadamente e interpretada qualitativamente com posterior agrupamento das narrativas: primeiro, por professores pré-serviço (alunas no último ano do curso de graduação em Letras) e professores em serviço (professoras já formadas em Letras ou não) e; segundo, por fatos revelados em duas situaçôes principais de interesse desta pesquisa, a saber:

(1) citações de pistas das abordagens (ou das próprias) que permearam os processos de aquisição dos falantes e aprendizes de LE/L2 e o fazer atual como professores;

(2) citações de pistas dos enfoques geral e específico (ou dos próprios) de ensino de línguas como metodologias da abordagem comunicativa ou como abordagens distintas.

Em cada agrupamento, citado acima, cada narrativa analisada recebeu um quadro (disponibilizados nos tópicos 2.1 e 2.2 deste artigo), onde as pistas reveladas foram posicionadas em três enfoques diferentes: gramatical, geral e especifico. Vale ressaltar que as interpretações das pistas foram realizadas levando em consideração o contexto da narrativa como um todo e não apenas o recorte feito nos quadros. Também no tópico 2.3 deste artigo, o mesmo quadro dos enfoques (em relação a cada narrativa analisada) foi apresentado, porém trazendo uma nova divisão entre o "antes" (como falantes e aprendizes de LE/ L2) e o "depois" (como professores LEs).

Embora a maioria dos falantes e aprendizes de LE/L2 que participaram desta pesquisa tenha permitido o uso de seus nomes verdadeiros, os mesmos foram preservados e, em contra partida, lhes foi atribuído números (ora às narradoras, ora às narrativas) de 1 a 16 . Para o uso das narrativas e/ou reprodução de parte das mesmas, neste trabalho, ${ }^{9}$ foi antecipadamente solicitado uma autorização por escrito a cada participante.

\footnotetext{
${ }^{9} \mathrm{E}$ também para repodução na página do projeto AMFALE (http://www.veramenezes.com/amfale.htm).
} 


\section{As lembranças reveladas: o processo de aquisição dos falantes e aprendizes de LE/L2 e o fazer atual como professores}

\section{Professores de LEs pré-serviço: algumas pistas sobre as abordagens}

Ao analisar as nove narrativas ${ }^{10}$ das professoras de LEs em pré-serviço (alunas do último ano do curso de graduação em Letras) foi possível perceber que apenas três delas (narrativas 1, 2 e 7) mencionaram algumas pistas das abordagens durante seus processos de aquisição de LE (apesar da solicitação prévia), conforme descrito a seguir.

A narradora 1 esclarece ter participado de aulas "conduzidas de forma mecânica" durante o ensino fundamental, provocando-lhe desânimo e medo de se expressar na língua inglesa, tendo apenas desenvolvido um amor pela língua-alvo ao conseguir desenvolver a oralidade durante sua permanência em uma escola de idiomas.

\begin{tabular}{|c|c|c|}
\hline \multicolumn{3}{|c|}{ Narrativa 1 } \\
\hline Enfoque gramatical & Enfoque geral & Enfoque específico \\
\hline - aulas conduzidas de maneira mecânica & - & - \\
\hline
\end{tabular}

A narradora 2 lembra-se dos estudos do verbo to be no ensino fundamental; dos role-plays nos livros didáticos utilizados nas salas de aula do ensino médio; da metodologia em sua primeira escola de idiomas, que lhe proporcionou um enriquecimento de vocabulário e a capacidade de se expressar na língua inglesa; do método que apenas revia regras gramaticais em sua segunda escola de idiomas, ocasião em que aprendeu pouco vocabulário; das aulas de inglês instrumental - consideradas por ela como uma metodologia "um pouco fria" - durante curso de análise de sistema, e; de que gostou bastante da disciplina Lingüística Aplicada na faculdade de Letras, tornandose, a partir dessa disciplina, mais crítica na escolha dos cursos de línguas e suas metodologias.

\footnotetext{
${ }^{10} \mathrm{Nas}$ partes transcritas das narrativas as palavras em negrito foram destacadas pela pesquisadora.
} 


\begin{tabular}{|c|c|c|}
\hline \multicolumn{3}{|c|}{ Narrativa 2} \\
\hline Enfoque gramatical & Enfoque geral & Enfoque específico \\
\hline $\begin{array}{l}\text { - Foram } 4 \text { anos aprendendo verbo to be. No } 1^{\circ} \\
\text { ano do ensino médio tive a oportunidade de ler } \\
\text { livros em LI, realizar role-plays (...); } \\
\text { - Nesse curso [escola de idiomas] apenas revi } \\
\text { regras gramaticais e adicionei poucas palavras } \\
\text { em meu vocabulário. }\end{array}$ & $\begin{array}{l}\text { - Entrei em um curso de } \\
\text { língua que dizia ter uma } \\
\text { metodologia diferente } \\
\text { (...) meu vocabulário } \\
\text { enriqueceu e comecei a } \\
\text { me comunicar (...) } \\
\text { através da LI. }\end{array}$ & $\begin{array}{l}\text { - (...) no curso de Analise } \\
\text { de Sistemas tive a experiência } \\
\text { de trabalhar com o inglês } \\
\text { instrumental. Gostei dessa } \\
\text { [metodologia] também, } \\
\text { mas achei um pouco 'fria' } \\
\text { pra mim. }\end{array}$ \\
\hline
\end{tabular}

A narradora 7 enfatiza que, inicialmente, gostava muito das aulas de inglês no ensino fundamental, pois havia música e incentivo por parte do professor para que os alunos se expressassem na língua-alvo. Nas aulas usava-se, também, repetir as "formas de cumprimento", associadas aos desenhos do material didático. No entanto, a narradora conta que foi se sentindo desmotivada pelos professores não "ensinarem como ela queria aprender". No ensino médio (ela narra), a falta de motivação continua pela não proficiência na língua-alvo dos professores, e foi só nas turmas avançadas de uma escola de idiomas que ela se motivou novamente, escolhendo o curso de Letras pelo amor a língua inglesa. $\mathrm{Na}$ faculdade, porém, sente-se bloqueada pelo pouco conhecimento de seus colegas com a língua-alvo. Já como professora de inglês, nas primeiras séries do ensino fundamental, se sente motivada a desenvolver em seus alunos o mesmo gosto pela língua inglesa que ora sentiu desenvolvendo em si mesma.

\begin{tabular}{|c|c|c|}
\hline \multicolumn{3}{|c|}{ Narrativa 7 } \\
\hline Enfoque gramatical & Enfoque geral & Enfoque específico \\
\hline - a professora passou na lousa as formas & $-(. .$.$) essa professora$ & \\
de cumprimento: good morning, good & trazia música, etc e & - \\
afternoon, good night/evening e fez os & fazia com que os & \\
respectivos desenhos. Ela falou as frases e & alunos falassem (...) & \\
fez com que nós repetíssemos as frases (...) & & \\
\hline
\end{tabular}

Nas narrativas 5, 6 e 8, o que chama mais atenção é a descrição das lembranças sobre as experiências afetivas e empáticas das aprendizes e falantes de LE (língua inglesa) com seus respectivos professores, revelando a importância desse fator para um início positivo, estimulador e agradável no processo de aquisição de LEs. Vejamos alguns depoimentos: 
"Comecei a estudar inglês quando fui para 5 a serie do ensino fundamental, a partir dai comecei a gostar muito, pois tinha uma excelente professora (...) que me fez com que me apaixonasse pela língua (...) fui para uma escola de idiomas (...) no meio da jornada tinha me desanimado por causa de uma professora (...) que não dava muita atenção e ria quando nós errávamos algo (...)." (narradora 5)

"Me matriculei em uma escola de idiomas e lá estudei 3 anos, no começo gostava de estudar, pois a professora tinha paciência para ensinar e era muito didática. Depois de 1 ano e meio com a mesma professora trocaram de professor, essa foi a pior coisa que aconteceu no periodo de estudos, porque essa nova professora só perguntava e conversava com os alunos que sabiam um pouco mais do que eu, isso me deixava muito brava, onde já se viu um professor discriminar um aluno que sabe menos que outro. No decorrer dos meus estudos, com essa nova professora, comecei a perder o interesse pela lingua, e ia para o curso porque a minha mãe me obrigava, eu comecei a não estudar mais para as provas que eram feitas no curso e ficava dispersa nas aulas e muitas vezes não compreendia coisas simples, me sentia um inútil dentro da sala de aula. Depois de um ano e meio resolvi sair da escola de idiomas e parei totalmente de estudar inglês (...) não quis estudar porque achava que os professores iam se comportar da mesma maneira." (narradora 6)

"Meu aprendizado de lingua inglesa iniciou-se no último ano do ensino fundamental que foi quando mudou a professora de inglês do meu colégio (...) e comecei a me interessar pela lingua." (narradora 8)

Nas demais narrativas (3, 4 e 9), as lembranças se referem tão somente ao aspecto cronológico do processo de aquisição de LE e à paixão ou não pela língua inglesa, porém sem vínculos diretamente marcados com os professores e/ou metodologias utilizadas.

\section{Professores de LEs em serviço: algumas pistas sobre as abordagens}

No estudo das sete narrativas ${ }^{11}$ das professoras de LEs em serviço foi possível constatar que apenas uma delas (narrativa 13) não mencionou quaisquer pistas das abordagens durante seu processo de aquisição de língua inglesa (LE) e, posteriormente, de ensino dessa LE, apesar da solicitação prévia. Já as narrativas 10,11, 12, 14, 15 e 16 mencionam algumas pistas, umas de

\footnotetext{
${ }^{11} \mathrm{Nas}$ partes transcritas das narrativas as letras em negrito foram destacadas pela pesquisadora.
} 
forma mais enfática $(10,11$ e 14) e outras de forma mais contida $(12,15$ e 16), conforme descrito a seguir.

A narradora 10 compartilha suas experiências com o aprendizado da língua portuguesa como segunda língua (L2). Ela nos conta que é falante nativa de língua inglesa (L1), residindo no Brasil por um tempo aproximado de dez anos, e enfatiza o seu fascínio inicial pelo som do português e as questôes pessoais (e do coração) que lhe motivaram a aprender a língua-alvo. Ela narra que sua aprendizagem da língua portuguesa iniciou-se ainda na França através do método audiolingual, momento em que se lembra apenas da parte visual exposta nos slides usados durante o curso. Uma vez no Brasil (ela conta), a aquisição do português ocorreu de forma natural no contato do dia-a-dia com os brasileiros, tendo tido apenas um ano de aulas formais na língua-alvo. Ela revela, também, que atualmente, após dez anos no Brasil, acredita ter atingindo um estado de fossilizaçãa $0^{12}$ em que confia na língua portuguesa já adquirida inviabilizando o aprendizado de novos vocabulários. Ela enfatiza que como professora de inglês no Brasil optou pelo uso de uma "abordagem humanista e comunicativa” em sala de aula, acreditando que um professor de língua deve analisar as necessidades e deficiências individuais de cada aluno numa tentativa de saná-las.

\begin{tabular}{|c|c|c|}
\hline \multicolumn{3}{|c|}{ Narrativa 10} \\
\hline Enfoque gramatical & Enfoque geral & Enfoque específico \\
\hline $\begin{array}{l}\text { - o professor usava o método } \\
\text { audiolingual, que consistia em projetar, } \\
\text { para os alunos, slides do João pegando um } \\
\text { trem. Nós tínhamos que repetir sentenças } \\
\text { sem sentido. }\end{array}$ & $\begin{array}{l}\text { - Eu ensino inglês } \\
\text { usando a abordagem } \\
\text { comunicativa } \\
\text { humanista (...) }\end{array}$ & $\begin{array}{l}\text { - Eu acredito, como } \\
\text { professora de língua, ser } \\
\text { necessário analisar as } \\
\text { necessidades de cada } \\
\text { aluno para veronde estão } \\
\text { suas falhas e atendê-las. }\end{array}$ \\
\hline
\end{tabular}

\footnotetext{
${ }^{12}$ De acordo com SELINKER (1972, p. 215, tradução da pesquisadora) o fenômeno de fossilização lingüística "consiste em itens lingüísticos, regras e subsistemas que os falantes de uma língua nativa particular tenderão a manter em sua interlíngua relativa a uma língua-alvo particular, independente de sua idade ou da quantidade de explicação e de instrução que ele possa receber na língua-alvo em questão".
} 
A narradora 11 expõe sua paixão pelas músicas dos Beatles e Rolling Stones como um incentivo natural no contato prévio com a língua inglesa, porém os estudos formais dessa língua, de base estruturalista (ela enfatiza), iniciaram-se no ensino fundamental e médio. Já na faculdade o método da gramática e tradução, presente nos estudos básicos de até então, é substituído por uma orientação audiolingualista, porém (ela relata) já se ouviam rumores de uma nova abordagem. Inicialmente, em sua atuação como professora de LE, ela esclarece ter utilizado os mesmos modelos de base estruturalista que a formaram. Com o tempo, passou a diversificar as aulas e a interagir mais com seus alunos, subvertendo a ordem estabelecida nos livros didáticos e trazendo assuntos de interesse para os mesmos em sala de aula, caminhando, assim, para o que acreditava ser os procedimentos da abordagem comunicativa. No entanto, uma reflexão consciente sobre sua abordagem de ensino iniciou-se apenas nos estudos da pós-graduação.

\begin{tabular}{|c|c|c|}
\hline \multicolumn{3}{|c|}{ Narrativa 11} \\
\hline Enfoque gramatical & Enfoque geral & Enfoque específico \\
\hline $\begin{array}{l}\text { - Sabia todas as letras e as traduçôes e o } \\
\text { dicionário era o meu grande aliado. Foi assim, } \\
\text { nesse autodidatismo inconsciente de gramática e } \\
\text { tradução que iniciou o meu interesse pela LI. } \\
\text { - Lembro-me do livro (...) de orientação } \\
\text { estruturalista: passe os exercícios para a } \\
\text { interrogativa, passe para a negativa, complete } \\
\text { com o verbo to be. } \\
\text { - no colegial (...) o método da gramática e } \\
\text { tradução continuou. } \\
\text { - na faculdade de Letras o estruturalismo, aliado } \\
\text { aos exercícios de orientação audioligualista } \\
\text { prosseguiu; } \\
\text { - [inicialmente] minha atuação em sala de } \\
\text { aula (...) não foi diferente dos modelos aos quais } \\
\text { tive contato (...) }\end{array}$ & $\begin{array}{l}\text { - Graduei-me (...) sem ter } \\
\text { ouvido falar na nova } \\
\text { abordagem (...) } \\
\text { - (...) como professora de } \\
\text { uma escola de idiomas (...) } \\
\text { a orientação do método era } \\
\text { voltada para a abordagem } \\
\text { comunicativa (...) } \\
\text { - Inconscientemente, adotava } \\
\text { procedimentos da aborda- } \\
\text { gem comunicativa, na } \\
\text { medida em que subvertia } \\
\text { (...) a ordem estabelecida } \\
\text { pelo material didático (...) } \\
\text { engajando-os [alunos] em } \\
\text { um processo de interação } \\
\text { cujos temas faziam mais } \\
\text { sentido para eles. }\end{array}$ & - \\
\hline
\end{tabular}

Na narrativa 14, é revelado um processo árduo e frustrante (em alguma medida) - desde o ensino fundamental e médio até a faculdade - de se aprender as línguas inglesa, espanhola e francesa através de métodos de cunho estruturalista e behaviorista. A narradora relata que suas experiências na aprendizagem dessas três línguas estrangeiras culminaram na evolução da 
aquisição apenas da língua inglesa e somente após a narradora ter tido a oportunidade de morar por dois anos nos Estados Unidos. A narradora enfatiza sua dificuldade em aprender uma língua estrangeira através de métodos tradicionais e que o processo de imersão na língua inglesa parece ter sido a única "metodologia" que lhe ajudou a adquirir o idioma.

\begin{tabular}{|c|c|c|}
\hline \multicolumn{3}{|c|}{ Narrativa 14} \\
\hline Enfoque gramatical & Enfoque geral & Enfoque específico \\
\hline $\begin{array}{l}\text { - Lembro-me de aprender os nomes das frutas, } \\
\text { os dias da semana, as estaçôes do ano e outras } \\
\text { listas parecidas (com o uso da LM) (...); } \\
\text { - (...) os alunos com mais habilidades na } \\
\text { língua-alvo eram os (...) que ganhavam } \\
\text { elogios, como os (...) reforçadores de } \\
\text { comportamento do áudio-lingualismo: very } \\
\text { good!, muy bien! } \\
\text { - näo conseguia entender os diálogos fabricados } \\
\text { (e muito menos reproduzi-los) nas fitas cassetes } \\
\text { que éramos obrigados a escutar para depois } \\
\text { reproduzi-los nos exercícios práticos de } \\
\text { conversação, sempre visando um tópico } \\
\text { gramatical especifico cobrado nas provas escritas, } \\
\text { nos ditados (que eu odiava!) e nas redaçôes. }\end{array}$ & - & - \\
\hline
\end{tabular}

A narradora 12 conta que morou em Québec (Canadá) durante quatro anos e foi nessa época que a língua francesa começou a fazer parte de sua vida. No primeiro ano em Québec ela se matriculou em um curso intensivo para imigrantes. Ela narra que uma professora em especial lhe marcou muito pelo jeito que ela ensinava e amava a língua francesa. As aulas incluíam muitos passeios culturais e textos de músicas e poesias na língua-alvo. A narradora atribui, também, a similaridade da língua portuguesa com a francesa, em termos das estruturas gramaticais, como um fator facilitador de seu processo de aquisição. De volta ao Brasil, ela começou a lecionar língua francesa, o que lhe deu muita satisfação. Nesse contexto ela percebeu que alguns alunos conseguiam aprender mais rápido do que outros, atribuindo a isso um "dom" de aprender. Como a narradora 14 , ela também acredita que a imersão na língua-alvo é fundamental para se poder dominar um novo idioma. 


\begin{tabular}{|c|c|c|}
\hline \multicolumn{3}{|c|}{ Narrativa 12 } \\
\hline Enfoque gramatical & Enfoque geral & Enfoque específico \\
\hline- & $\begin{array}{l}\text { - [a professora] utilizava um método } \\
\text { interessante, e complementava as aulas } \\
\text { com outros textos, músicas, poesia e } \\
\text { toda a sua experiência cultural. }\end{array}$ & - \\
\hline
\end{tabular}

A narradora 15 revela o seu contato com a língua espanhola já na infância com o seu pai e avós paternos espanhóis, o que a fez compreender perfeitamente a língua desde muito pequena, embora sua fluência tenha sido mesmo adquirida depois de morar durante seis meses em Barcelona (Espanha), já na fase adulta. Quando volta ao Brasil ela passa a ministrar aulas particulares de espanhol e a conversação era o foco de suas aulas, exatamente por não conhecer muitos os métodos de ensino de língua. No entanto, isso lhe pareceu ser um incômodo para alguns de seus alunos, exatamente por ela não conseguir explicar com a clareza necessária algumas regras gramaticais da língua espanhola. Passados dois anos ela conseguiu aprovação no exame superior do DELE ${ }^{13} \mathrm{e}$ a ministrar aulas em uma escola particular de idiomas onde recebeu treinamento, passando a ter mais confiança em sala de aula.

\begin{tabular}{|c|c|c|}
\hline \multicolumn{3}{|c|}{ Narrativa 15} \\
\hline Enfoque gramatical & Enfoque geral & Enfoque específico \\
\hline- & $\begin{array}{l}\text { - [em Barcelona] assisti a desenhos } \\
\text { infantis com a minha priminha } \\
\text { espanhola [e] foi a forma mais eficaz } \\
\text { que encontrei no começo para aprender } \\
\text { a me comunicar. (...) comecei a dar aulas } \\
\text { particulares de espanhol (...). Tive alguns } \\
\text { alunos que progrediram muito bem, } \\
\text { apesar de eu não conhecer muitos } \\
\text { métodos. Como tinha fluência, meu } \\
\text { enfoque era bastante centrado na } \\
\text { conversação, o que às vezes incomodava } \\
\text { os alunos, porque era evidente que eu não } \\
\text { sabia explicar algumas regras com a } \\
\text { clareza necessária. }\end{array}$ & - \\
\hline
\end{tabular}

${ }^{13}$ Diploma de Espanhol como Língua Estrangeira, do Instituto Cervantes. 
A narradora 16 relata seu envolvimento com a língua inglesa (LE) através de músicas, ouvindo rádio, e seu fascínio e realização pessoal quando pôde finalmente, após alguns anos de persistência, compreender as mensagens que as músicas transmitiam. Durante o ensino fundamental e médio, as experiências, marcadamente chatas (ela narra), foram com o ensino do verbo to be, ano após ano. Em uma escola particular de idiomas, as aulas chatas, cansativas e sofridas (ela relata) continuaram, porém a ênfase na pronúncia a fez melhorar consideravelmente. Ela conta que depois das músicas, e já na faculdade, veio o seu envolvimento e novamente fascínio com a literatura norte-americana e também com a língua francesa. No entanto, o aprendizado do francês e suas literaturas foi bem difícil, opressor e entediante (ela esclarece) e o mesmo gosto desenvolvido pelo inglês não ocorreu com o francês. Ao ministrar aulas de inglês seu aprendizado da língua melhorou, porém, em sala de aula (ela conta), se limitou a seguir os livros didáticos e se sentiu "robotizada" pela rotina imposta aos professores pela escola. Ela finalizou sua narrativa enfatizando que o aprendizado de uma língua vai além da gramática e que seu contato com as culturas norte-americana e francesa lhe proporcionou um crescimento pessoal e intelectual importante.

\begin{tabular}{|c|c|c|}
\hline \multicolumn{3}{|c|}{ Narrativa 16} \\
\hline Enfoque gramatical & Enfoque geral & Enfoque específico \\
\hline $\begin{array}{l}\text { - Eu comecei a aprender inglês na escola } \\
\text { (...). Todo ano do ginásio a professora de } \\
\text { inglês mudava, e todas (...) começam } \\
\text { com o verbo "to be"; } \\
\text { - [Escola de idiomas] Aulas e mais aulas } \\
\text { sobre os mesmos temas (...) cansativo, } \\
\text { chato, sofrido. Pouco espaço para a } \\
\text { realidade do aluno (...) assistir o filme } \\
\text { Baby - o porquinho (...) ou um trecho } \\
\text { de um romance americano enlatado que } \\
\text { não te diz nada (...). As provas eram } \\
\text { burocráticas (...). } \\
\text { - Comecei a dar aulas por acaso (...). } \\
\text { Muitas vezes eu abria o livro didático e } \\
\text { lá estavam as partes do carro em inglês. } \\
\text { Era só ir seguindo a aula, colocando o } \\
\text { cd (...) Há escolas dizendo que o (...) fill } \\
\text { in the blanks é inútil,, porque as pessoas } \\
\text { não fazem isso na vida real. Eu discordo } \\
\text { totalmente. }\end{array}$ & $\begin{array}{l}\text { - Eu comecei a estudar francês com } \\
\text { uma nativa muito culta, que } \\
\text { estudava cultura indu, japonesa, } \\
\text { africana, oriental em geral (...). O } \\
\text { contato com a riqueza intelectual } \\
\text { que essas aulas me ofereceram foi } \\
\text { extraordinário e mudou a minha } \\
\text { visão de mundo. (...) Eu só posso } \\
\text { dizer que o aprendizado de uma } \\
\text { lingua, seja ela qual for, é muito } \\
\text { mais do que o conhecimento da } \\
\text { gramática ou de como pedir um } \\
\text { prato num restaurante. }\end{array}$ & - \\
\hline
\end{tabular}




\section{$O$ antes e 0 depois: as abordagens que permearam o processo de aquisição dos falantes e aprendizes de LE/L2 e as escolhas em sala de aula}

As narrativas 1, 2, 3, 4, 5, 6, 8 (professoras de LEs pré-serviço) e 14 (professora de LEs em serviço) não mencionam se estavam ministrando aulas de língua estrangeira ou se já haviam ministrado antes, apesar da solicitação prévia. Já as narradoras 7,9 (professoras de LEs pré-serviço) e 12 e 13 (professoras de LEs em serviço), embora citem em suas narrativas que ministravam e/ou ministraram aulas de língua inglesa, não deixaram claro quaisquer pistas das metodologias utilizadas em sala de aula, como segue:

“(...) ao dar aulas (...) vejo o aluno como se fosse eu naquele momento em que tomara o gosto pelo idioma e fico tentando fazer que eles gostem tanto quanto eu gostava das aulas de Inglês. " (narrativa 7)

“(...) meu primeiro emprego, aos 16 anos, foi de professora de inglês, aprendi muito com essa profissão." (narrativa 9)

"Então comecei a dar aulas (...). Percebo pelos meus alunos que alguns possuem o dom de aprender, conseguem em pouco tempo já falar bem, entendem a língua e gostam. Outros porém já apresentam dificuldades, resistências em aprender, estão lá porque precisam, então tudo se torna mais lento, e às vezes, desestimulante!" (narrativa 12)

"Quando comecei a dar aulas, meu conhecimento acho que triplicou, talvez até mais que isso! Ensinar foi para mim a melhor forma de aprender." (narrativa 13)

Já as narrativas 10, 11, 15 e 16 (professoras de LEs em serviço) deixaram algumas pistas sobre suas ações em sala de aula. Vejamos:

As narradoras 10 e 11 mostraram processos parecidos em suas narrativas que revelaram uma abordagem (estrutural; enfoque gramatical) na aquisição de L2/LE e outra (comunicativa; enfoque geral) em suas atuaçóes em salas de aula (como professoras de LE) - provavelmente, envolvendo todo um processo de reflexão e amadurecimento acadêmico e profissional, na área específica de ensino de línguas, entre um momento e outro, como destacado nos quadros que seguem: 


\begin{tabular}{|c|c|c|c|c|c|}
\hline \multicolumn{6}{|c|}{ Narrativa 10} \\
\hline \multicolumn{3}{|c|}{$\begin{array}{c}\text { ANTES } \\
\text { (como aprendiz de português, L2) }\end{array}$} & \multicolumn{3}{|c|}{$\begin{array}{c}\text { DEPOIS } \\
\text { (como professora de inglês, LE) }\end{array}$} \\
\hline $\begin{array}{l}\text { Enfoque } \\
\text { gramatical }\end{array}$ & $\begin{array}{c}\text { Enfoque } \\
\text { geral }\end{array}$ & $\begin{array}{l}\text { Enfoque } \\
\text { específico }\end{array}$ & $\begin{array}{l}\text { Enfoque } \\
\text { gramatical }\end{array}$ & $\begin{array}{l}\text { Enfoque } \\
\text { geral }\end{array}$ & $\begin{array}{l}\text { Enfoque } \\
\text { específico }\end{array}$ \\
\hline $\begin{array}{l}\text { - O professor usava o } \\
\text { método audiolingual, } \\
\text { que consistia em projetar, } \\
\text { para os alunos, slides do } \\
\text { João pegando um trem. } \\
\text { Nós tínhamos que repetir } \\
\text { sentenças sem sentido (...) }\end{array}$ & - & - & - & $\begin{array}{l}\text { Eu ensino in- } \\
\text { glês usando a } \\
\text { abordagem } \\
\text { comunicativa } \\
\text { e humanista } \\
\text { (...) }\end{array}$ & $\begin{array}{l}\text { - Eu acredito, como } \\
\text { professora de lingua, } \\
\text { ser necessário analisar } \\
\text { as necessidades de } \\
\text { cada aluno para ver } \\
\text { onde estão suas falhase } \\
\text { atendê-las. }\end{array}$ \\
\hline
\end{tabular}

\begin{tabular}{|c|c|c|c|c|c|}
\hline \multicolumn{6}{|c|}{ Narrativa 11} \\
\hline \multicolumn{3}{|c|}{$\begin{array}{c}\text { ANTES } \\
\text { (como aprendiz de inglês, LE) }\end{array}$} & \multicolumn{3}{|c|}{$\begin{array}{c}\text { DEPOIS } \\
\text { (como professora de inglês, LE) }\end{array}$} \\
\hline $\begin{array}{l}\text { Enfoque } \\
\text { gramatical }\end{array}$ & $\begin{array}{c}\text { Enfoque } \\
\text { geral }\end{array}$ & $\begin{array}{l}\text { Enfoque } \\
\text { específico }\end{array}$ & $\begin{array}{c}\text { Enfoque } \\
\text { gramatical }\end{array}$ & $\begin{array}{l}\text { Enfoque } \\
\text { geral }\end{array}$ & $\begin{array}{l}\text { Enfoque } \\
\text { específico }\end{array}$ \\
\hline $\begin{array}{l}\text { - Foi assim, nesse autodi- } \\
\text { datismo inconsciente de } \\
\text { gramática e tradução que } \\
\text { iniciou o meu interesse } \\
\text { pela LI. } \\
\text { - Lembro-me do livro (...) } \\
\text { de orientação estrutura- } \\
\text { lista: passe os exercícios } \\
\text { para a interrogativa, passe } \\
\text { para a negativa, complete } \\
\text { com o verbo to be. } \\
\text { - (...) no colegial (...) o } \\
\text { método da gramática e } \\
\text { tradução continuou. } \\
\text { - (...) na faculdade de } \\
\text { Letras o estruturalismo, } \\
\text { aliado aos exercícios de } \\
\text { orientação audioligua- } \\
\text { lista prosseguiu; }\end{array}$ & - & - & - & $\mid \begin{array}{lr}- \text { [inicialmen- } \\
\text { te] } & \text { minha } \\
\text { atuação em } \\
\text { sala de } & \text { aula } \\
\text { (..) } & \text { não foi } \\
\text { diferente } & \text { dos } \\
\text { modelos aos } \\
\text { quais tive } \\
\text { contato (...) }\end{array}$ & $\begin{array}{l}\text { - [como professora] } \\
\text { inconscientemente, } \\
\text { adotava procedimen- } \\
\text { tos da abordagem } \\
\text { comunicativa, na } \\
\text { medida em que sub- } \\
\text { vertia (...) a ordem } \\
\text { estabelecida pelo ma- } \\
\text { terial didático (...) } \\
\text { engajando-os [alu- } \\
\text { nos] em umprocesso de } \\
\text { interação cujos temas } \\
\text { faziam mais sentido } \\
\text { para eles. }\end{array}$ \\
\hline
\end{tabular}

Já as lembranças das narradoras 15 e 16 mostraram que os processos envolvidos na aquisição de LE (como aprendizes de LE/L2) continuaram os mesmos ao ministrarem alunas de LEs. No entanto, esses processos pareceram ser diferentes na medida em que as experiências foram distintas, demonstrando 
também e possivelmente - diferentemente do que foi percebido nas narrativas 10 e 11 - a falta de um processo de reflexão e amadurecimento acadêmico e profissional, na área específica de ensino de línguas, entre um momento e outro.

A narradora 15, por exemplo, exterioriza suas experiências no país da língua estrangeira que adquiriu. Essas experiências de contato real e significado, e não formal, com a língua-alvo, através da conversação dia-a-dia com nativos e/ou pela mídia, a fez - uma vez atuando como professora, mas com poucos conhecimentos sobre abordagens e métodos de ensino de línguas - transferir para a sua sala de aula as mesmas experiências vividas, ou seja, muita conversação e poucos esclarecimentos sobre a gramática da língua-alvo, como acontece no uso de qualquer língua fora dos contextos formais das escolas.

\begin{tabular}{|c|c|c|c|c|c|}
\hline \multicolumn{6}{|c|}{ Narrativa 15} \\
\hline \multicolumn{3}{|c|}{$\begin{array}{c}\text { ANTES } \\
\text { (como aprendiz de espanhol, LE) }\end{array}$} & \multicolumn{3}{|c|}{$\begin{array}{c}\text { DEPOIS } \\
\text { (como professora de espanhol, LE) }\end{array}$} \\
\hline $\begin{array}{l}\text { Enfoque } \\
\text { gramatical }\end{array}$ & $\begin{array}{c}\begin{array}{c}\text { Enfoque } \\
\text { geral }\end{array} \\
\end{array}$ & $\begin{array}{l}\text { Enfoque } \\
\text { específico }\end{array}$ & $\begin{array}{c}\text { Enfoque } \\
\text { gramatical }\end{array}$ & \begin{tabular}{c|}
$\begin{array}{c}\text { Enfoque } \\
\text { geral }\end{array}$ \\
\end{tabular} & $\begin{array}{l}\text { Enfoque } \\
\text { específico }\end{array}$ \\
\hline- & $\begin{array}{l}\text { - [em Barcelona] assisti } \\
\text { desenhos infantis (...) } \\
\text { foi a forma mais eficaz } \\
\text { que encontrei no come- } \\
\text { ço para aprender a me } \\
\text { comunicar. (...) }\end{array}$ & 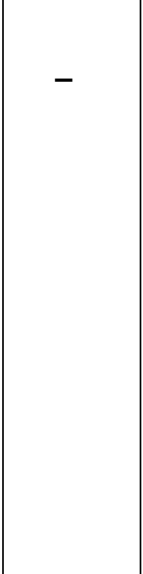 & - & $\begin{array}{l}\text { - Comecei a dar aulas } \\
\text { particulares (...) } \\
\text { - Tive alguns alunos } \\
\text { que progrediram muito } \\
\text { bem, apesar de eu não } \\
\text { conhecer muitos méto- } \\
\text { dos. Como tinha fluên- } \\
\text { cia, meu enfoque era } \\
\text { bastante centrado na } \\
\text { conversação, o que às } \\
\text { vezes incomodava os } \\
\text { alunos, porque era evi- } \\
\text { dente que eu não sabia } \\
\text { explicar algumas regras } \\
\text { com a clareza necessária. }\end{array}$ & - \\
\hline
\end{tabular}

A narradora 16, por sua vez, mostra certo enfado e/ou descontentamento em seu processo de aquisição de LE ora baseado em um enfoque gramatical, porém ao ministrar aulas de LE acaba se sentindo como parte do mesmo processo - agora imposto pela instituição de que faz parte - pelo qual esteve inserida inicialmente, o que, possivelmente, a fez utilizar alguns procedimentos comuns do enfoque gramatical. 


\begin{tabular}{|c|c|c|c|c|c|}
\hline \multicolumn{6}{|c|}{ Narrativa 16} \\
\hline \multicolumn{3}{|c|}{$\begin{array}{c}\text { ANTES } \\
\text { (como aprendiz de inglês, LE) }\end{array}$} & \multicolumn{3}{|c|}{$\begin{array}{c}\text { DEPOIS } \\
\text { (como professora de inglês, LE) }\end{array}$} \\
\hline $\begin{array}{l}\text { Enfoque } \\
\text { gramatical }\end{array}$ & $\begin{array}{c}\text { Enfoque } \\
\text { geral }\end{array}$ & $\begin{array}{r}\text { Enfoque } \\
\text { específico }\end{array}$ & $\begin{array}{l}\text { Enfoque } \\
\text { gramatical }\end{array}$ & $\begin{array}{c}\text { Enfoque } \\
\text { geral }\end{array}$ & $\begin{array}{l}\text { Enfoque } \\
\text { específico }\end{array}$ \\
\hline $\begin{array}{l}\text { - Eu comecei a aprender } \\
\text { inglês na escola (...). Todo } \\
\text { ano do ginásio a professora } \\
\text { de inglês mudava e todas } \\
\text { (...) começam com o verbo } \\
\text { "to be"; } \\
\text { - [Escola de idiomas] } \\
\text { Aulas e mais aulas sobre os } \\
\text { mesmostemas (...) cansativo, } \\
\text { chato, sofrido. Pouco espaço } \\
\text { para a realidade do aluno } \\
\text { (...) assistir o filme Baby- } \\
\text { o porquinho (...) ou um } \\
\text { trecho de um romance } \\
\text { americano enlatado que } \\
\text { não te diz nada (...). As } \\
\text { provas eram burocráticas } \\
\text { (...). }\end{array}$ & $\mid$\begin{tabular}{|c|}
$\mid$ \\
\end{tabular} & - & $\begin{array}{l}\text { - Comecei a dar aulas por } \\
\text { acaso (...) Muitas vezes eu } \\
\text { abria o livro didático e lá } \\
\text { estavam as partes do carro } \\
\text { em inglês. Era só ir seguindo } \\
\text { a aula, colocando o cd (...) } \\
\text { Há escolas dizendo que o } \\
\text { (...) fill in the blanks é inútil, } \\
\text { porque as pessoas não fazem } \\
\text { isso na vida real. Eu discordo } \\
\text { totalmente. }\end{array}$ & 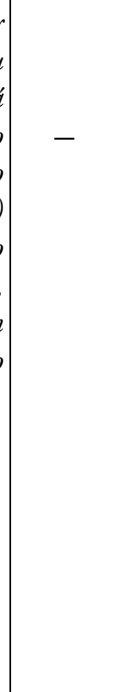 & - \\
\hline
\end{tabular}

\section{Um pequeno panorama das apropriações das visões contemporâneas de ensino de línguas em professores de LEs pré-serviço e em serviço: as menções aos enfoques geral e específico}

$\mathrm{Na}$ análise de todas as narrativas participantes desta pesquisa percebeuse que em apenas duas delas (2 e 10) houve citações ao enfoque específico, embora as mesmas não mencionassem concretamente quaisquer pistas que se pudesse afirmar que suas visões fossem do enfoque como metodologia da abordagem comunicativa ou como uma abordagem independente. No entanto, a narradora 2 (professor de LE pré-serviço) ao explicitar o termo inglês instrumental utilizado em um curso de Análise de Sistemas durante a sua formação, pareceu compreendê-lo como metodologia, tendo em vista que em um parágrafo anterior ela narrou que entrou "em um curso de língua que dizia ter uma metodologia diferente" e, em seguida, e depois de citar o inglês instrumental, colocou que gostou "dessa também". O pronome demonstrativo "essa" sugere que ela estaria se referindo ao termo "metodologia" citado anteriormente, demonstrando compreender, dessa forma, o enfoque específico 
como uma metodologia e não como uma abordagem distinta daquela "metodologia diferente" que, provavelmente, deva ser uma referência ao enfoque geral (comunicativo). Assim, se poder-se-ia inferir (de forma apenas especulativa) que a narradora 2 compreenderia que tanto o enfoque geral quanto o específico seriam metodologias da abordagem comunicativa.

Da mesma forma, a narradora 10 (professor de LE em serviço) explicitou que ensina a língua inglesa "usando a abordagem comunicativa e humanista" e depois narrou que acredita "ser necessário analisar as necessidades de cada aluno". Sabe-se que a 'análise de necessidades' é um dos pilares do enfoque específico e/ou inglês instrumental. Sendo assim, compreende-se que nessas citaçóes a narradora poderia estar se referindo ao enfoque geral especifico, respectivamente, como fazendo parte de um todo coeso, ou seja, como metodologias de uma mesma abordagem, a comunicativa.

\section{Considerações finais}

Apesar do reduzido número de narrativas coletadas, dados importantes no que se refere à formação pré e continuada de professores de LEs são revelados nesta pesquisa. Nota-se que o tema "abordagem" (e suas metodologias) é desenvolvido com mais facilidade pelas narradoras com pósgraduação em Lingüística Aplicada (LA) do que pelas narradoras no último semestre da graduação em Letras e das professoras formadas em outras áreas que não Letras, influenciando diretamente nas reflexóes dos próprios processos de aquisição e, conseqüentemente, nas próprias atuações como professoras de LEs, no que se refere à escolha consciente de uma abordagem que conduzirá às ações em sala de aula. Isso mostra a relevância do referido tema (abordagens e suas metodologias) tratado na disciplina LA, principalmente nos cursos de graduação em Letras e na formação dos professores de LEs como um todo, tendo em vista que são poucos os(as) professores(as) de LEs formados em Letras (ou não) que procuram (por diversas razões, não exploradas aqui) os cursos de pós-graduação em LA, na área de ensino/aprendizagem de LE/L2, antes de atuarem na profissão. Muitos aprendizes e falantes de L2/LE acabam se tornando professores de LEs apenas devido às suas experiências com a língua-alvo, desconsiderando a importância de uma formação específica na área.

No que concerne às menções aos enfoques geral e específico, embora pouco referidos - e talvez a esse respeito a presente pesquisa deveria ter sido mais específica ao solicitar a redação das narrativas -, percebe-se que os mesmos 
são interpretados como metodologias e, muito provavelmente, metodologias da abordagem comunicativa (e não como abordagem distintas), e isso tanto para os professores de LEs pré-serviço (no último ano de graduação em Letras) quanto para os professores de LEs em serviço (com pós-graduação em LA). Isso revela um pequeno panorama da atual apropriação e/ou compreensão desses dois enfoques (geral e específico) entre os professores de LEs pré-serviço e em serviço no contexto brasileiro atual, servindo, também, como um dado importante para se juntar à discussão revelada na introdução deste artigo.

\begin{abstract}
The goal of this paper is to diagnose the references to the foreign language teaching approaches that permeate the acquisition processes of speakers and learners of FL/SL by collecting learner history narratives, as well as to reflect on how these memories influenced the usage of a given approach in the classroom as these individuals act as foreign language teachers. Special attention was given to the language teaching for specific purposes either as an approach or as a methodology of the communicative approach as described by the learners. In general, the results have shown that the grammatical approach was the one that actually permeated the acquisition processes and the acts of teaching. However, this conclusion changed significantly when the responses of teachers with a master's degree in Applied Linguistics were considered. Language teaching for specific purposes, by its turn, was little mentioned in the narratives, and yet it was considered as a methodology of the communicative approach.
\end{abstract}

KEY-WORDS: narrative, foreign language teaching approach, FL/SL acquisition

\title{
Referências bibliográficas
}

ABRAHĀO, M. H. V. Conflitos e incertezas do professor de lingua estrangeira na renovação de sua prática de sala de aula. 1996. Tese (Doutorado em Lingüística Aplicada) - Instituto de Estudos da Linguagem, UNICAMP, 1996.

ALMEIDA FILHO. J. C. P. Dimensões comunicativas no ensino de línguas. Campinas: Pontes, 1998.

ALMEIDA FILHO. J. C. P. Análise de abordagem como procedimento fundador de auto-conhecimento e mudança para o professor de língua estrangeira. In: ALMEIDA FILHO, J. C. (Org.). O professor de LE em formaçãa. Campinas, SP: Pontes, 1999.

ANDRADE, L. A. C. An analysis of L2 learning process, 2006. Disponível em http://www.veramenezes.com/artigos.htm. Acesso em 13 de julho de 2007. 
ANTHONY, E. M. Approach, method, and technique. English Teaching Forum, v. 3, n. 1, p. 7-10, 1965.

BARCELOS, A. M. F. Narrativas, crenças e experiências de aprender inglês. Linguagem \& Ensino, v. 9, n. 2, p. 145-175, jul./dez, 2006.

BORGES, E. F. V. Discernimento do esteio teórico nos PCN de língua estrangeira - ensino fundamental. 2003. Dissertação (Mestrado em Lingüística Aplicada) - Instituto de Estudos da Linguagem, UNICAMP, 2003.

BORGES, E. F. V. Montante e jusante em um projeto de ensino/aprendizagem de língua estrangeira (inglês) no contexto brasileiro. Contexturas, n. 10, p. 95-106, 2006. BOHN, V. C. R. As estratégias de aprendizagem de professores de língua inglesa, 2006. Disponível em: <http://www.veramenezes.com/artigovanessa.htm>. Acesso em: 13 jul. 2007.

CARDOSO, K. P. D.; LIMA, D. C. Sinais de variáveis afetivas e de autonomia em narrativas de aprendizagem de inglês como língua estrangeira, 2006. Disponível em: $<$ http://www.veramenezes.com/diogafetivo.htm>. Acesso em: 13 jul. 2007.

CARDOSO, R. C. T. O imaginário do comunicativo entre professores de língua estrangeiralinglês (e sua confrontação com a teoria externa). 2002. Tese (Doutorado em Filologia e Lingüística) - Faculdade de Ciências e Letras, UNESP, Assis, 2002. CASTAÑOS, F. Dez contradições do enfoque comunicativo. Trabalhos em Lingüistica Aplicada, v. 21, p. 65-78, 1993.

CELANI, M. A. A. Ensino de línguas estrangeiras: olhando para o futuro. In: CELANI, M. A. A. (Org.). O ensino de segunda lingua: redescobrindo as origens. São Paulo: EDUC, 1997. p. 147-161.

FRANCO, M. S.; ALVARENGA, M. B. Mapeamento do perfil do (a) professor (a) de inglês das escolas públicas de piracicaba: formação e competências, 2006. Disponível em: <http://www.veramenezes.com/mapcomp.htm\#_ftn1>. Acesso em: 13 jul. 2007.

HOWATT, A. P. R. From structural to communicative, Annual Review of Applied Linguistic, v. 8, p. 14-19, 1988.

HOWATT, A. P. R.; WIDDOWSON, H. H. A history of English language teaching. $2^{\text {nd }}$ ed. Oxford: Oxford University Press, 2004.

HUTCHINSON, T.; WATERS, A. How communicative is ESP? ELT Journal, v. 38, n. 2, p.108-113, 1984.

HUTCHINSON, T.; WATERS, A. English for specific purposes: a learning-centred approach. Cambridge: Cambridge University Press, 1987.

MOITA LOPES, L. P. Pesquisa interpretativa em lingüística aplicada: a linguagem como condição e solução. D.E.L.T.A., v. 10, n. 2, p. 329-338, 1994. 
PAIVA, V. L. M. O. Autonomia e complexidade. Linguagem \& Ensino, v. 9, n. 1, p. 77-127, 2006.

RAMOS, R. C. G. Instrumental no Brasil: a desconstrução de mitos e a construção do futuro. In: FREIRE, M. M. et al. (Org.). Lingüistica aplicada e contemporaneidade. Campinas-SP: Pontes, 2005.

SEF/MEC. Parâmetros curriculares nacionais: $3^{\circ}$ e $4^{\circ}$ ciclos do ensino fundamental: língua estrangeira, Brasília: MEC/SEF, 1998.

SELINKER, L. Interlanguage. International Review of Applied Linguistics, v. 10, p. 209-231, 1972.

TELLES, J. A. A trajetória narrativa: histórias sobre a prática pedagógica e a formação do professor de linguas. In: GIMENEZ, T. (Org.). Trajetórias na formação de professores de línguas. Londrina: Ed. UEL, 2002. p. 15-38.

WATERS, A. ESP - Things fall apart? RELC Regional Seminar. Singapore, 1993.

WIDDOWSON, H. G. Communicative and community: the pragmatics of ESP. English for Specific Purpose, v. 17, n. 1, p. 3-14, 1998.

WILKINS, D. A. Notional syllabuses. London: Oxford University Press, 1976.

WILLIANS, M.; BURDEN, R. L. Psychology for language teacher: a social constructvist approach. Cambridge: Cambridge University Press, 1997.

Recebido em novembro de 2007. Aprovado em janeiro de 2008. 